\title{
A clinical study on ectopic pregnancy in tertiary care hospital Imphal
}

\author{
Naorem Sunanda Chanu ${ }^{1}$, Vinodkumar Suresh Basavaradder ${ }^{2 *}$, Cibi Darsani ${ }^{1}$, \\ Ahanthembi Sanaton ${ }^{1}$
}

\author{
${ }^{1}$ Department of Obstetrics and Gynecology, JNIMS, Imphal, Manipur, India \\ ${ }^{2}$ Department of Obstetrics and Gynecology, Basaveshwar Medical College, Chitradruga, Karnataka, India
}

Received: 19 November 2020

Revised: 05 January 2021

Accepted: 06 January 2021

\section{*Correspondence: \\ Dr. Vinodkumar Suresh Basavaradder, \\ E-mail: vinodkumarsb19@gmail.com}

Copyright: (c) the author(s), publisher and licensee Medip Academy. This is an open-access article distributed under the terms of the Creative Commons Attribution Non-Commercial License, which permits unrestricted non-commercial use, distribution, and reproduction in any medium, provided the original work is properly cited.

\begin{abstract}
Background: Ectopic pregnancy is one of the most common life-threatening emergencies in early trimester of pregnancy. The aim of this study was to determine the incidence, age group, gravidity, parity, risk factors, clinical presentation, treatment modalities associated with ectopic pregnancy in the current scenario.

Methods: We conducted a prospective study for the period of two years starting from Aug 2017 to Aug 2019 at JNIMS OBG Department.

Results: A total of 94 patients who were diagnosed as ectopic pregnancy and they were analysed for clinical presentation, risk factors, operative findings and treatment modality. Majority of patients were in the age group of 25 to 30 years. Ectopic pregnancy was more commonly associated with history of prior abortions, prior LSCS and PID. Commonly presented with amenorrhea of 6-8 weeks with abdominal pain and bleeding PV, most common site being ampulla followed by isthmus. Most of the patients had ruptured pregnancy at presentation. Majority of the patients underwent salpingectomy and salpingectomy with contralateral tubectomy.

Conclusions: Ectopic pregnancy diagnosis is a grey zone and challenging. Early diagnosis by keeping suspicion in first trimester with PV bleeding and pain abdomen with history of amenorrhea about ectopic pregnancy, which helps in management to reduce maternal morbidity and even mortality.
\end{abstract}

Keywords: Abortion, Ectopic pregnancy, LSCS, Pelvic inflammatory disease

\section{INTRODUCTION}

One of the nightmares for expectant mothers is ectopic pregnancy. An ectopic pregnancy occurs when a fertilized ovum implants outside the normal uterine cavity. ${ }^{1,2}$ It is a life-threatening condition and one of the commonest acute abdominal emergencies in day to day practice affecting approximately $2 \%$ of all pregnancies. ${ }^{3}$ It is the most important cause of maternal mortality and morbidity in the first trimester. ${ }^{4}$

Despite the relatively high frequency of occurrence, early detection is not always easy. Up to half the patients with ectopic pregnancy present to emergency department, the condition is not identified at the initial medical assessment. ${ }^{5}$ There has been an increase in the frequency of ectopic pregnancy in the past few years is due to a number of risk factors which include pelvic inflammatory disease, after IVF and related techniques and availability of better diagnostic techniques. ${ }^{6}$ PID is the commonest cause of ectopic pregnancy. ${ }^{6}$ Ectopic pregnancy is gaining more importance now a days because of its impact on women fertility. ${ }^{7}$ The current trend in management of these pregnancies is tubal conservative procedures be it chemotherapeutic agents or conservative surgical approaches. ${ }^{8,9}$ 


\section{METHODS}

This was a prospective study conducted at the JNIMS Hospital, Imphal during the period of two years starting from August 2017 to August 2019 after obtaining ethical committee clearance from the hospital authorities. All patients with history suggestive of ectopic pregnancy and in whom diagnosis was confirmed by clinical examination, ultrasound or direct observation during operation were included in the study. Detailed history, clinical findings, risk factors, ultrasonography findings, intra operative findings of all patients were noted and entered in excel sheet. The statistical analysis was done using statistical package for social sciences (SPSS) Version 21. There were no exclusion criteria.

\section{RESULTS}

Total number of pregnant females examined in the JNIMS OPD during our study period was 4560. Out of which 94 females were found to have ectopic pregnancy. The incidence of ectopic pregnancy was found to be $2.06 \%$

\section{Age distribution}

Around $40.2 \%(n=38)$ of patients with ectopic pregnancy were in the age group of 25-30 years. Ectopic pregnancy was found to be rare below 20 years and above 40 years age, accounting for $7.4 \% \quad(n=7)$ and $6.3 \% \quad(n=6)$ respectively. The age distribution of the ectopic pregnancy is given in Table 1,

Table 1: Age distribution of ectopic pregnancy.

\begin{tabular}{|l|l|}
\hline Age (in years) & $\begin{array}{l}\text { Percentage of ectopic pregnancy } \\
\text { patients (number) }\end{array}$ \\
\hline$<\mathbf{2 0}$ & $7.4(7)$ \\
\hline $\mathbf{2 0 - 2 5}$ & $21(20)$ \\
\hline $\mathbf{2 5 - 3 0}$ & $40.2(38)$ \\
\hline $\mathbf{3 0 - 4 0}$ & $24.3(23)$ \\
\hline $\mathbf{> 4 0}$ & $6.3(6)$ \\
\hline
\end{tabular}

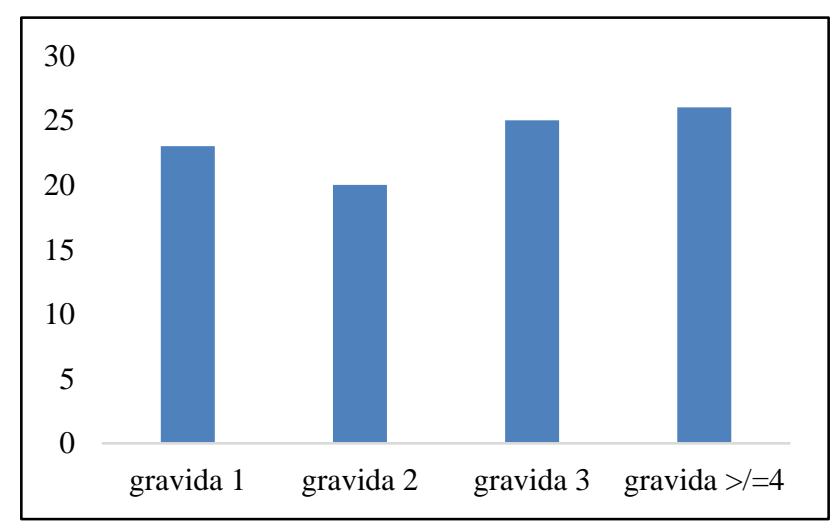

Figure 1: Ectopic pregnancy distribution according to the gravida.

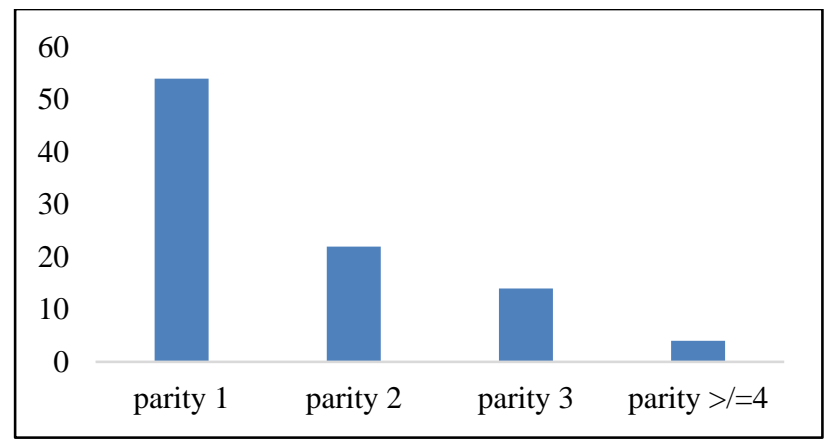

Figure 2: Ectopic pregnancy distribution according to the parity.

\section{Gravida}

Ectopic pregnancy was found most commonly in patients with gravida 4 or more, i.e. around $27.5 \%(n=26)$ of total ectopic pregnancies, followed by Gravida 3 with $26.5 \%$ $(n=25)$. The results are given in Figure 1.

\section{Parity}

Ectopic pregnancy was mostly seen in patients with parity with around $57.2 \% \quad(n=54)$ ectopic pregnancies lying in this group, followed by parity 2 and parity 3 accounting for $23.3 \%(n=22)$ and $14.8 \%(n=14)$ of total ectopic pregnancies. The results are given in Figure 2.

\section{Risk factors}

Around $27.5 \%$ patients had no risk factors for ectopic pregnancy. Among the known risk factors most common risk factor for ectopic pregnancy was found to be abortion in $23.3 \%(n=22)$ of patients, followed by history of previous LSCS $19.8 \%(n=18)$, pelvic inflammatory disease $19 \%(n=18)$ and patients who underwent MTP $12.7 \%(n=12)$. The various risk factors for ectopic pregnancy found in this study are shown in Figure 3.

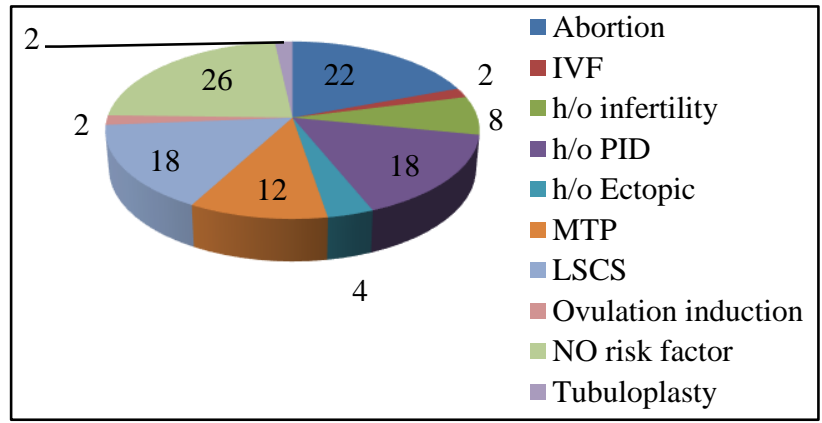

Figure 3: Risk factors for ectopic pregnancy.

\section{Amenorrhea}

Most of the patients had history of amenorrhea of around 6-8 weeks $73.1 \%(n=69)$. Only $2.1 \%$ patients presented after 1st trimester (Table 2). 
Table 2: Number of weeks of amenorrhea at time of presentation in ectopic pregnancy patients.

\begin{tabular}{|ll|}
\hline $\begin{array}{l}\text { No. of weeks of } \\
\text { amenorrhea }\end{array}$ & $\begin{array}{l}\text { Percentage of ectopic pregnancy } \\
\text { patients (number) }\end{array}$ \\
\hline$\leq \mathbf{5}$ & $8.4(8)$ \\
\hline $\mathbf{5 - 6}$ & $6.3(6)$ \\
\hline $\mathbf{6 - 8}$ & $73.1(69)$ \\
\hline $\mathbf{8 - 1 2}$ & $9.5(9)$ \\
\hline $\mathbf{> 1 2}$ & $2.1(2)$ \\
\hline
\end{tabular}

\section{Site of ectopic pregnancy}

Most common site of ectopic pregnancy was found to be ampulla of fallopian tube in $60.4 \% \quad(n=57)$ of cases followed by isthmus $25.4 \%(n=24)$. Results are shown in, Figure 4.

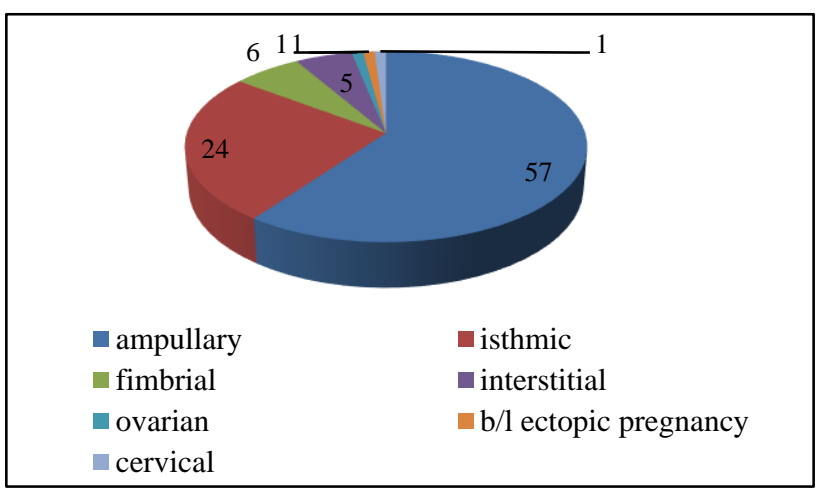

Figure 4: Distribution of sites of ectopic pregnancy.

\section{Clinical features}

93.2\% $(n=88)$ patients presented with pain abdomen which was the most common presenting complains. $89 \%$ $(\mathrm{n}=84)$ patients presented with per vaginal bleeding. Around $41.3 \%(n=39)$ presented in shock. Results are shown in Table 3.

Table 3: Clinical features at the time of presentation in ectopic pregnancy patients.

\begin{tabular}{|ll|}
\hline Clinical features & $\begin{array}{l}\text { Percentage of ectopic } \\
\text { pregnancy patients (number) }\end{array}$ \\
\hline Pain abdomen & $93.2(88)$ \\
\hline H/O amenorrhea & $91.1(86)$ \\
\hline P/V bleeding & $89.0(84)$ \\
\hline Presented in shock & $41.3(39)$ \\
\hline
\end{tabular}

\section{Intraoperative findings}

Majority of the patients i.e. $60.4 \%(n=57)$ had ruptured ectopic while only $23.3 \%(n=22)$ patient had unruptured pregnancy. Tubal abortion was seen in $6.3 \%(n=6)$ cases while chronic ectopic was seen in $4.2 \% \quad(n=4)$ cases. Results are shown in Figure 5.

\section{Management}

Majority of the patients underwent salpingectomy i.e. $46.6 \% \quad(n=44)$. Salpingectomy with contralateral tubectomy was done in $33.9 \% \quad(n=32)$ cases. Salpingostomy and salpingo-ophorectomy was done in $6.3 \%(n=6)$ cases each. Results are shown in Figure 6.

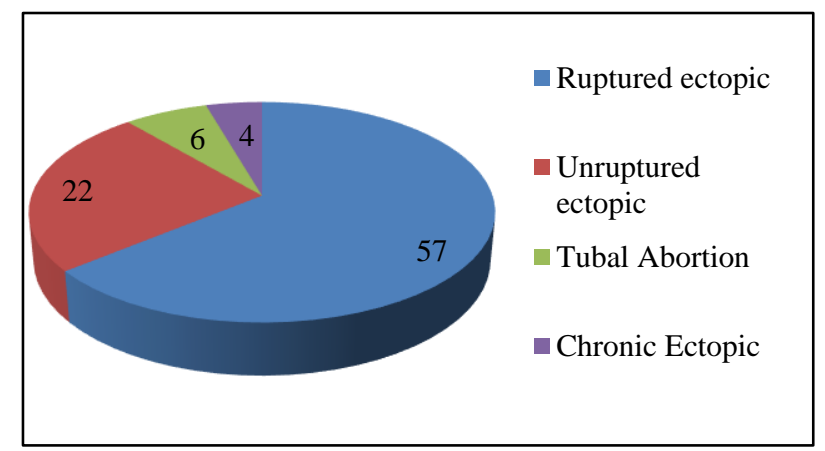

Figure 5: Intra-operative findings in patients with ectopic pregnancy.

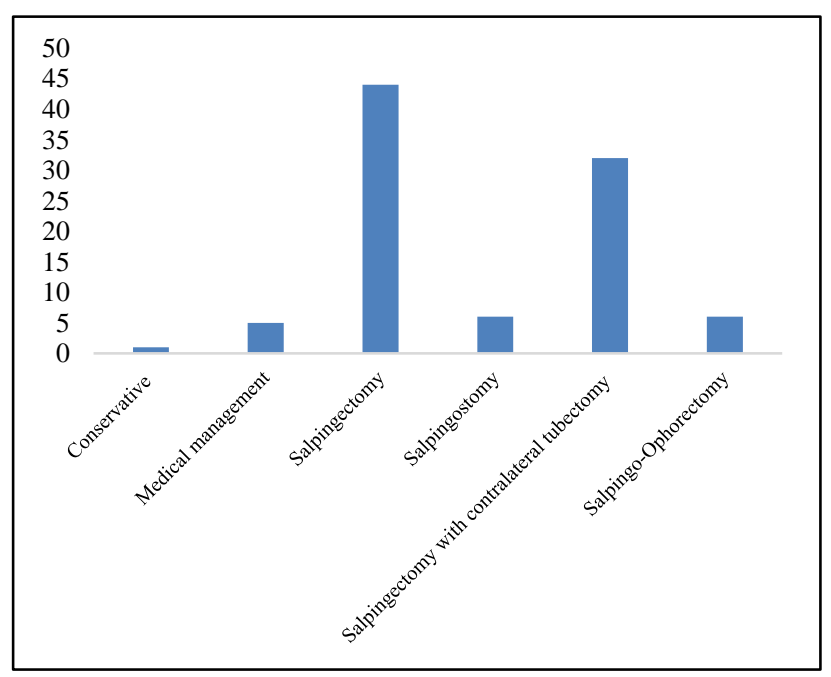

Figure 6: Management in ectopic pregnancy.

\section{DISCUSSION}

Motherhood is a dream of every woman. This dream is not always pleasant and may have some nightmares through her journey. Ectopic pregnancy is one such nightmare and a life-threatening emergency. Ectopic pregnancy is a life-threatening emergency in obstetrics. It is one of the most common causes of first trimester maternal deaths.

The prevalence of same varies from 6 to $16 \%$ globally. Its incidence has been increasing, complicating 0.25 to $2 \%$ of all pregnancies. It accounts for 3.5 to $7.1 \%$ of maternal mortality in India. In the present study, the incidence is $2.06 \%$, higher than that found in other studies in developing countries $(0.56-1.5 \%)$. 
In the present study, most of the cases belonged to the age group of 25 to 30 years $(40.2 \%)$, similar to observations from studies from developing countries. Younger age group has high prevalence because they are more active sexually hence are predisposed to sexually transmitted infections, pelvic inflammatory disease and their sequelae. In the present study, maximum number of ectopic pregnancies were associated with higher birth order. In contrast, in the ICMR multi -centric case control study of ectopic pregnancy, majority of women were young and had low parity $(73 \%) .{ }^{10}$ Amongst the risk factors studied, history of having previous abortion was the most common finding $(23.3 \%)$, similar to the observations found in other studies conducted by Maji et al $(26.1 \%)$ and Muffi et al $(21.05 \%) .^{11,12}$

In our study, $8.4 \%$ of infertile women had ectopic pregnancy, similar results were observed in studies done by Samiya et alnine, however, this association was found $15.1 \%$ in Rose et al study, $11.2 \%$ in Arora et al study. ${ }^{13}$

In our study group, most of the women belonged to low socioeconomic status and theyhave poor personal hygiene and lack of immunity; hence they were predisposed to pelvic inflammatory disease, which is a risk factor for ectopic pregnancy. Endo- salpingitis leads to ectopic implantation by damaging the mucosa and entrapping the migrating embryo. It gives rise to peri tubal adhesions, thereby impairing the peristaltic movements, leading to inadequate transportation of embryo.

However, the most important fact which needs attention is that in majority of the cases $(27.5 \%)$, there was no recognizable risk factor. This stresses the fact that to diagnose ectopic pregnancy, we must be ectopic minded. Most common associated symptom of ectopic pregnancy is abdominal pain and bleeding per vagina. Most of the patients presented at gestational age of 6 to 8 weeks in present study, similar to what found in studies by Khaleeque et al. ${ }^{14}$ Fallopian tube was the most common site of ectopic, ampulla $(60.4 \%)$ being the commonest site in fallopian tube. Amenorrhoea was seen in $73.1 \%$ of cases, similar results were found in studies done Pal A et al $(78.5 \%) .{ }^{15}$

Ruptured ectopic pregnancy was present in $60.4 \%$ cases and tubal abortion in $6.3 \%$ cases, similar to results of Shetty et al $(61.3 \%$ and $12.9 \%$ respectively). In present study $23.3 \%$ of cases had unruptured ectopic which is correlating with the study done by Gaddagi et al, and chronic ectopic pregnancy was seen in $4.2 \%$ of cases in the current study. ${ }^{16,17}$

Salpingectomy $(46.6 \%)$ by open method was the most common modality of treatment. Out of this $33.9 \%$ cases had salpingectomy with contralateral tubectomy by modified Pomeroy's method as they were not desirous of further child bearing. Salpingostomy was done in $3.75 \%$ cases of unruptured ectopic pregnancy. Laparotomy with salpingectomy was the most common modality of treatment in other studies too. There was no maternal mortality due to ectopic pregnancy in the current study. However various studies have reported maternal mortality ranging from $0 \%$ to $1.3 \%$

\section{Limitations}

Since the study was conducted in a single institute, the duration being for two years only. The major limitation were the case strength and duration of the study and the cases were not followed up during the study for the adverse outcomes.

\section{CONCLUSION}

Incidence of ectopic pregnancy is increasing in the last two to three decades as a risk factor like PID, artificial reproductive techniques is increasing. Diagnosis of ectopic pregnancy by clinically and with TVS and serum beta HCG in high risk women and management of ectopic pregnancy as early as possible, either by medical and surgical techniques, which impact on future fertility and even prevent mortality.

\section{ACKNOWLEDGMENTS}

Authors would like to thank Dr. Shruti and Mr. Pramod N. K. for their help in supporting and helping in the study.

\section{Funding: No funding sources Conflict of interest: None declared \\ Ethical approval: The study was approved by the Institutional Ethics Committee}

\section{REFERENCES}

1. Varma R, Gupta J. Tubal ectopic pregnancy. BMJ Clin Evid. 2009;2009:1406.

2. Walker JJ. Ectopic pregnancy. Clin Obstet Gynecol. 2007;50:89-99.

3. Gary CF, Leveno KJ, Bloom SL, Hauth JC, Rouse DJ, Spong CY. Williams obstetrics. Ectopic pregnancy. 23rd edition. McGrew-Hill Companies. 2010:238-254.

4. Mahboob U, Mazhar SB. Management of ectopic pregnancy: a two-year study. J Ayub Med Coll Abbottabad. 2006;18(4):34-7.

5. Karaer A, Avsar FA, Batioglu S. Risk factors for ectopic pregnancy: a case-control study. Aust NZJ Obstet Gynaecol. 2006;46:521-7.

6. Diquelou JY, Pia P, Tesquier L, HenrySuchet J, Gicquel JM, Boyer S. The role of Chlamydia trachomatis in the infectious etiology of extra-uterine pregnancy. J Gynecol Obstet Biol Reprod. 1988; $17: 325-32$.

7. Rajkhowa M, Glass MR, Rutherford AJ, Balen AH, Sharma V, Cuckle HS. Trends in the incidence of ectopic pregnancy in England and Wales from 1966 to 1996 . BJOG. 2000;107:369-74. 
8. Sultana CJ, Easley K, Collins RL. Outcome of laparoscopic vs traditional surgeries for ectopic pregnancies. Fertil Steril. 1992;57:285.

9. Delacruz A, Cumming DC. The factors which determine the fertility after a conservative or radical surgical treatment for ectopic pregnancy. Fertil Steril. 1997;868:71.

10. ICMR-task free project. Multicentric case control study of ectopic pregnancy in India. J Obstet Gynaecol India. 1990;40:425-30.

11. Majhi AK, Roy N, Karmakar KS, Banerjee PK. Ectopic pregnancy: an analysis of 180 cases. J Indian Med Assoc. 2007;105(6):308-12.

12. Mufti S, Rather S, Mufti S, Rangrez RA, Wasiqa K. Ectopic pregnancy: an analysis of 114 cases. JK Pract. 2012;17(4):20-3

13. Shagufta SM, Samiya M, Reyaz AR, Wasiqa K. Ectopic pregnancy; an anlysis of 114 cases. JK Practitioner. 2012;17(4):20-3.
14. Khaleeque F, Siddiqui RI, Jafarey SN. Ectopic pregnancies: a three year study. J Pak Med Assoc. 2001;51(7):240-2.

15. Pal A, Gupta KB, Sarin R. A study of ectopic pregnancy and high risk factors in Himachal Pradesh. Indian Med Assoc. 1996;94(5):172-3.

16. Shetty S, Shetty A. A clinical study of ectopic pregnancies in a tertiary care hospital of Mangalore, India. Innov J Med Health Sci. 2014;4(1).

17. Gaddagi RA, Chandrashekhar AP. A clinical study of ectopic pregnancy. JCDR. 2012;6(5):867-9.

Cite this article as: Chanu NS, Basavaradder VS, Darsan C, Sanaton A. A clinical study on ectopic pregnancy in tertiary care hospital Imphal. Int J Reprod Contracept Obstet Gynecol 2021;10:562-6. 